\title{
Density Functional Theory Study on Defect Feature of $\mathrm{As}_{\mathrm{Ga}} \mathbf{G a}_{\mathrm{As}}$ in Gallium Arsenide
}

\author{
Deming Ma, Xi Chen, Hongbo Qiao, Wei Wang, Wei Shi, and Enling Li \\ Department of Applied Physics, Xian University of Technology, Xian 710054, China \\ Correspondence should be addressed to Deming Ma; xautmdm@163.com
}

Received 1 September 2014; Accepted 12 January 2015

Academic Editor: Meiyong Liao

Copyright (C) 2015 Deming Ma et al. This is an open access article distributed under the Creative Commons Attribution License, which permits unrestricted use, distribution, and reproduction in any medium, provided the original work is properly cited.

\begin{abstract}
We investigate the defect feature of $\mathrm{As}_{\mathrm{Ga}} \mathrm{Ga}_{\mathrm{As}}$ defect in gallium arsenide clusters in detail by using first-principles calculations based on the density functional theory (DFT). Our calculations reveal that the lowest donor level of $\mathrm{As}_{\mathrm{Ga}} \mathrm{Ga}_{\mathrm{As}}$ defect on the gallium arsenide crystal surface is $0.85 \mathrm{eV}$ below the conduction band minimum, while the lowest donor level of the $\mathrm{As}_{\mathrm{Ga}} \mathrm{Ga}_{\mathrm{As}}$ defect inside the gallium arsenide bulk is $0.83 \mathrm{eV}$ below the bottom of the conduction band, consistent with gallium arsenide EL2 defect level of experimental value $(\mathrm{Ec}-0.82 \mathrm{eV})$. This suggests that $\mathrm{As}_{\mathrm{G}_{\mathrm{a}}} \mathrm{Ga}_{\mathrm{As}}$ defect is one of the possible gallium arsenide EL2 deep-level defects. Moreover, our results also indicate that the formation energies of internal $\mathrm{As}_{\mathrm{Ga}} \mathrm{Ga}_{\mathrm{As}}$ and surface $\mathrm{As}_{\mathrm{Ga}} \mathrm{Ga}_{\mathrm{As}}$ defects are predicted to be around $2.36 \mathrm{eV}$ and $5.54 \mathrm{eV}$, respectively. This implies that formation of $\mathrm{As}_{\mathrm{Ga}} \mathrm{Ga}_{\mathrm{As}}$ defect within the crystal is easier than that of surface. Our results offer assistance in discussing the structure of gallium arsenide deep-level defect and its effect on the material.
\end{abstract}

\section{Introduction}

As a kind of excellent semiconductor material, gallium arsenide is widely used in fast photoelectric devices and integrated circuit substrate [1] and so forth. As a compound semiconductor material, the defect problems of the undoped semi-insulating GaAs (SI-GaAs), in particular, the unique deep-level defects in the SI-GaAs single crystal material, such as EL2 $(\mathrm{Ec}-0.82 \mathrm{eV})$ and EL6 $(\mathrm{Ec}-0.38 \mathrm{eV})$, which have an important influence on the photoelectric characteristics and the application of materials [2-7], are more complex than those of silicon and germanium. By various theoretical and experimental means, many researchers have studied the microstructures of gallium arsenide EL2 deep-levels. For example, Lagowski et al. put forward isolated $\mathrm{As}_{\mathrm{Ga}}$ antisite defect structure type [8], Wager and van Vechten put forward $\mathrm{V}_{\mathrm{Ga}} \mathrm{As}_{\mathrm{Ga}} \mathrm{V}_{\mathrm{Ga}}$ ternary complex defect structure type [9], Zou et al. put forward $\mathrm{As}_{\mathrm{Ga}} \mathrm{V}_{\mathrm{As}} \mathrm{V}_{\mathrm{Ga}}$ ternary complex defect structure type $[10,11]$, and Morrow proposes the possible $\mathrm{As}_{\mathrm{Ga}} \mathrm{V}_{\mathrm{Ga}}$ defect structures [12]. Wosinski et al. pointed out that EL2 is not isolated defects [13]. The steady and metastable energy levels of EL2 in semi-insulating GaAs were studied by Kabiraj and Ghosh [14]. Ternary complex defect model of EL2 defect has been studied by using first-principles by Li et al. [7], and EL2 and EL6 defects and correlations of clusters have been preliminarily discussed by Zhao and $\mathrm{Wu}$ [15]. These results have a certain role in promoting of the features and applications of gallium arsenide materials. On the basis of the above study on gallium arsenide clusters and defects preliminary [16-19], in this paper, the $\mathrm{As}_{\mathrm{Ga}} \mathrm{Ga}_{\mathrm{As}}$ defect and its features have been studied by first-principles based on density functional theory (DFT), which gives out another kind of microstructure of gallium arsenide EL2 deep-level defects and offers assistance in the discussion of defect features of gallium arsenide deep-level and application of materials.

\section{Computational Methods}

Our total energy and electronic structure calculations were carried out within a revised Heyd-Scuseria-Ernzerhof (HSE06) range-separated hybrid functional as implemented in VASP code [20,21]. In the HSE06 approach, the screening parameter $\mu=0.2 \AA^{-1}$ and the Hartree-Fock (HF) mixing parameter $\alpha=25 \%$ which meant $25 \%$ HF exchange with 75\% GGA of Perdew, Burke, and Ernzerhof (PBE) [22] 

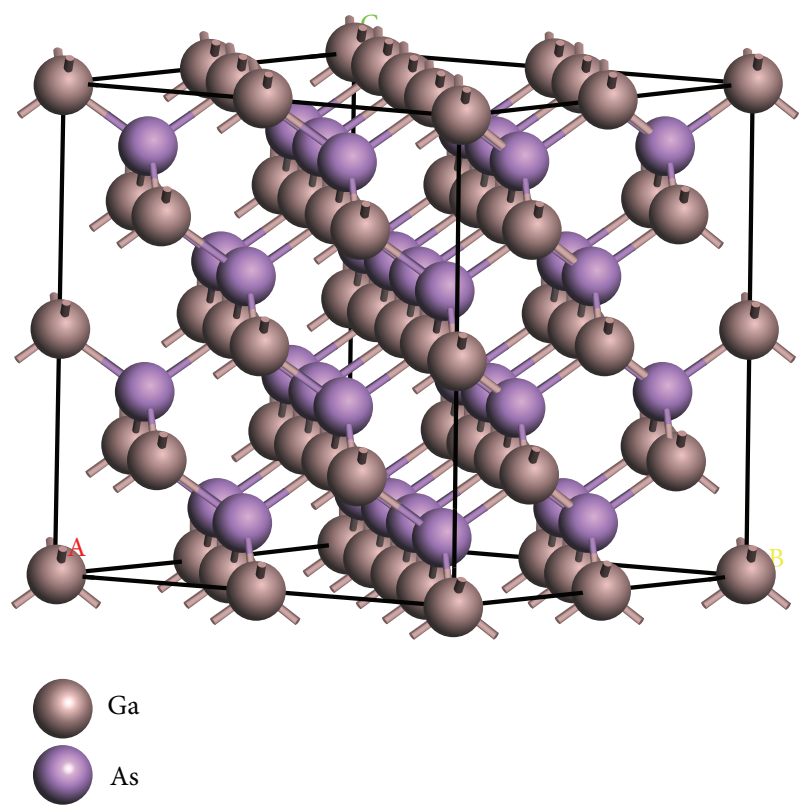

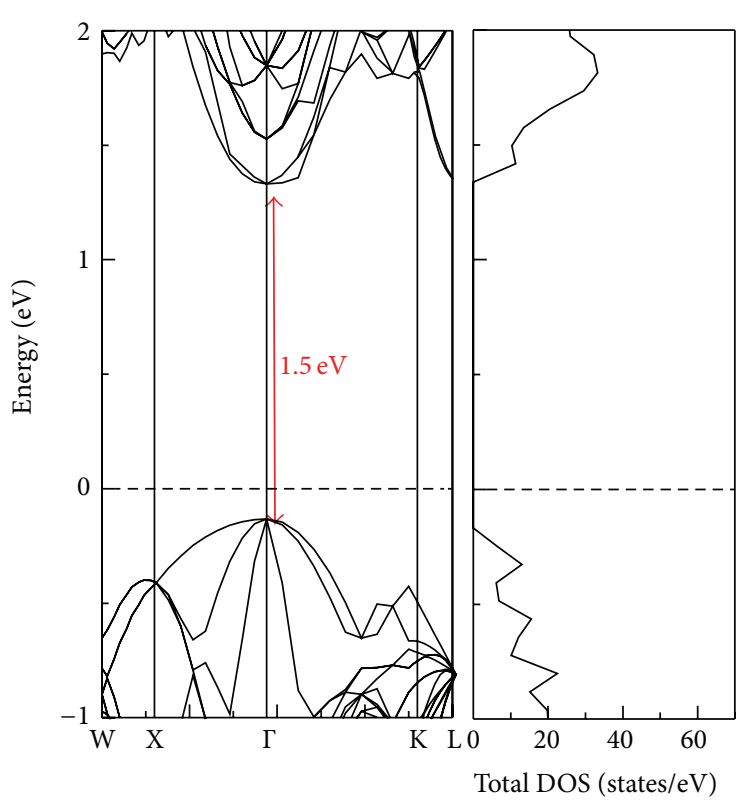

(b)

Figure 1: (a) Supercell structure model of perfect GaAs. (b) Band structure and the total DOS of perfect GaAs. The Fermi energy is set to zero.

exchange were chosen to well reproduce the experimental band gap $(\sim 1.43 \mathrm{eV})$ of GaAs. The core-valence interaction was described by the frozen-core projector augmented wave (PAW) method [23, 24]. The electronic wave functions were expanded in a plane wave basis with a cut-off of $300 \mathrm{eV}$. A $3 \times 3 \times 3$ k-point mesh within Monkhorst-Pack scheme [25] was applied to the Brillouin-zone integrations in total energy calculations. The internal coordinates in the defective supercells were relaxed to reduce the residual force on each atom to less than $0.02 \mathrm{eV} \cdot \AA^{-1}$. All defect calculations were spin-polarized. In the calculation, firstly, defect structure models in various conditions were optimized and then static self-consistent calculation to the ground state structure was conducted and, finally, the corresponding band structure and density of states (DOS) were obtained.

\section{Results and Discussions}

3.1. The Properties of Perfect GaAs. Figure 1(a) shows the perfect GaAs supercell structure model. Figure 1(b) shows the calculated band structure and total density of states (DOS) of the perfect GaAs supercell structure model.

As can be seen from Figure 1(b), the perfect GaAs has a direct band gap structure, and its band gap is $1.5 \mathrm{eV}$ at the $\Gamma$ point, which is very close to the experimental value $(1.43 \mathrm{eV})$, implying that the selected parameters are reasonable.

3.2. Surface Doping $A s_{G a} G a_{A s}$ Defect. Figure 2(a) shows the supercell structure model of GaAs (001) surface doping $\mathrm{As}_{\mathrm{Ga}} \mathrm{Ga}_{\mathrm{As}}$ complex defect. The crystal thickness and vacuum thickness are $8.24 \AA$ and $20.00 \AA$, respectively. The length of the base vectors $\mathrm{A}$ and $\mathrm{B}$ is for both $15.99 \AA$, whereas the length of the base vector $\mathrm{C}$ is $28.24 \AA$. Furthermore, vector angles $\alpha, \beta$, and $\gamma$ are all $90^{\circ}$. Figure 2(b) shows the band structure and the total DOS of the GaAs (001) surface $\mathrm{As}_{\mathrm{Ga}} \mathrm{Ga}_{\mathrm{As}}$ complex defect model.

As can be seen from Figure 2(b), the lowest donor defect level of the $\mathrm{As}_{\mathrm{Ga}} \mathrm{Ga}_{\mathrm{As}}$ defect on the gallium arsenide crystal surface is $0.85 \mathrm{eV}$ below the bottom of the conduction band, being consistent with gallium arsenide EL2 defect level of experimental value $(\mathrm{Ec}-0.82 \mathrm{eV})$, which suggests that $\mathrm{As}_{\mathrm{Ga}} \mathrm{Ga}_{\mathrm{As}}$ defect is one of the possible microstructures of gallium arsenide EL2 deep-level defects, and the formation energy of $\mathrm{As}_{\mathrm{Ga}} \mathrm{Ga}_{\mathrm{As}}$ defect is $5.54 \mathrm{eV}$.

One can note that the existence of $\mathrm{As}_{\mathrm{Ga}} \mathrm{Ga}_{\mathrm{As}}$ defect changes the band structure and the total DOS of GaAs. This leads to the formation of dangling bond between the neighbors of defects. As a result, the matching surface states can exchange their positions with holes and electrons of the gallium arsenide materials, which affected the photoelectric properties of GaAs materials directly.

3.3. Internal Doping $A s_{G a} G a_{A s}$ Defect. The supercell structure model of the internal deep layer doping $\mathrm{As}_{\mathrm{Ga}} \mathrm{Ga}_{\mathrm{As}}$ defect is displayed in Figure 3(a). The distance between the $\mathrm{As}_{\mathrm{Ga}} \mathrm{Ga}_{\mathrm{As}}$ defect and the upper interface is $5.65 \AA$. Figure $3(\mathrm{~b})$ shows the supercell structure model of the internal shallow layer doping $\mathrm{As}_{\mathrm{Ga}} \mathrm{Ga}_{\mathrm{As}}$ defect, and the distance between the $\mathrm{As}_{\mathrm{Ga}} \mathrm{Ga}_{\mathrm{As}}$ defect and the upper interface is $2.83 \AA$. Figures 4 (a) and 4(b) show the corresponding band structure and total DOS, respectively.

As can be seen from Figure 4 , the band structure and DOS of internal $\mathrm{As}_{\mathrm{Ga}} \mathrm{Ga}_{\mathrm{As}}$ defect are insensitive to its position. 


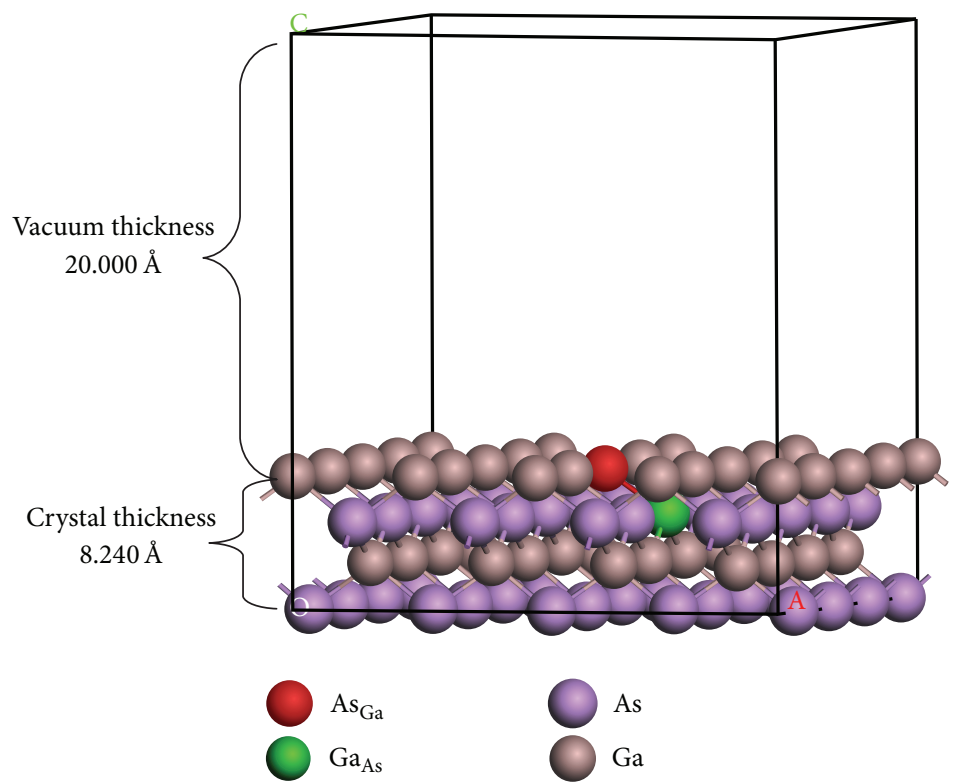

(a)

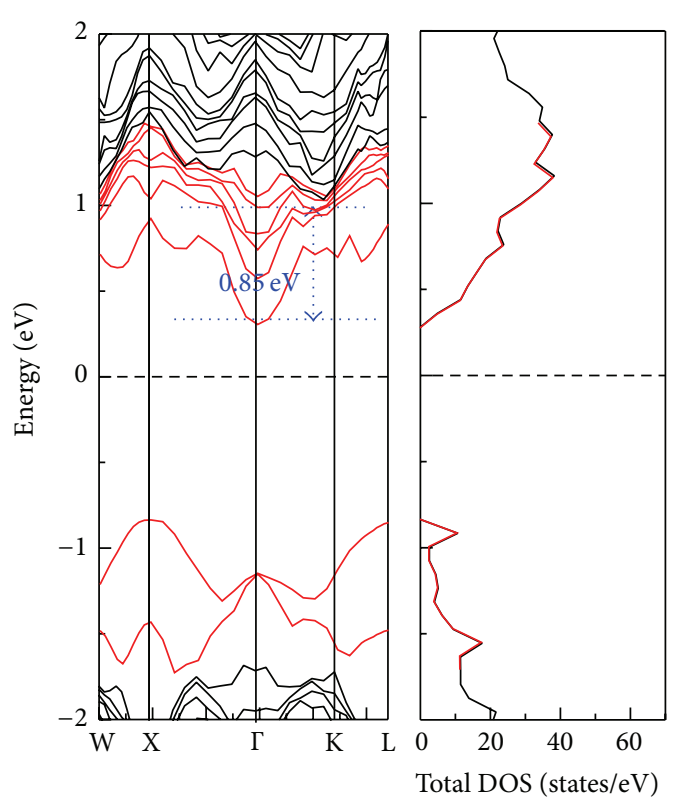

(b)

FIGURE 2: (a) Supercell structure model of the surface double antisite $\mathrm{As}_{\mathrm{Ga}} \mathrm{Ga}_{\mathrm{As}}$ defect. (b) The band structure and the total DOS of GaAs (001) surface with double antisite $\mathrm{As}_{\mathrm{Ga}} \mathrm{Ga}_{\mathrm{As}}$ defect.

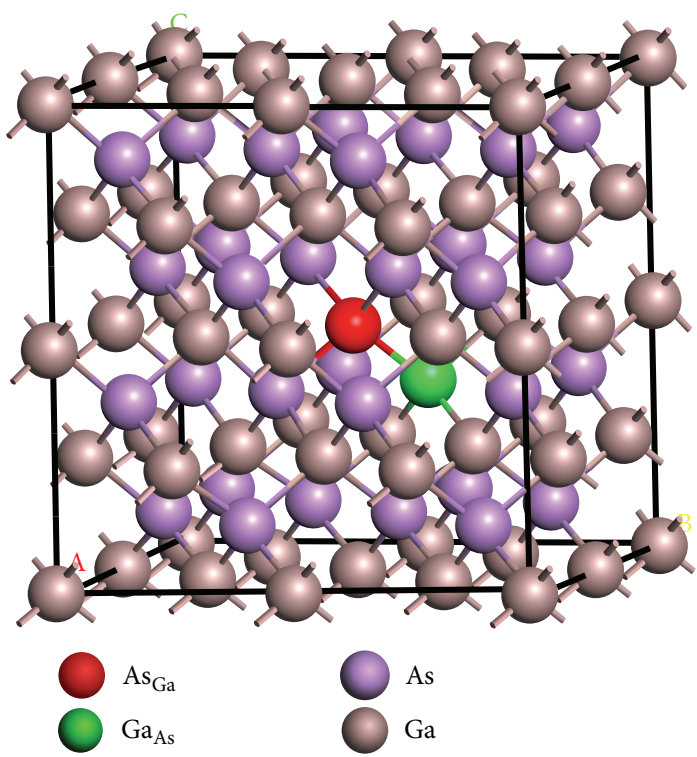

(a)

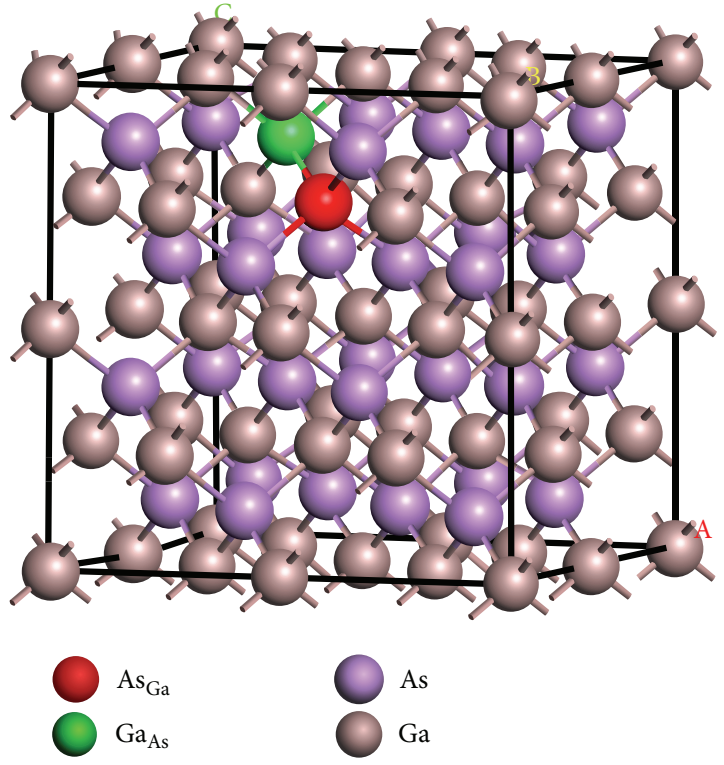

(b)

FIGURE 3: Supercell structure model of internal double antisite $\mathrm{As}_{\mathrm{Ga}} \mathrm{Ga}_{\mathrm{As}}$ defects. (a) Between the $\mathrm{As}_{\mathrm{Ga}} \mathrm{Ga}_{\mathrm{As}}$ defects and the upper interface the distance is $5.653 \AA$. (b) The distance between the $\mathrm{As}_{\mathrm{Ga}} \mathrm{Ga}_{\mathrm{As}}$ defects and the upper interface is $2.827 \AA$.

The lowest donor defect level is below the bottom of the conduction band $0.83 \mathrm{eV}$, being consistent with gallium arsenide EL2 defect level of experimental value $(\mathrm{Ec}-0.82 \mathrm{eV})$. This suggests that internal $\mathrm{As}_{\mathrm{Ga}} \mathrm{Ga}_{\mathrm{As}}$ defect is one of possible gallium arsenide EL2 deep-level defects. Meanwhile, it increases donor level and acceptor level of defects, changes the total DOS of materials, and affects the photoelectric properties of GaAs materials directly, when comparing with the band structure of perfect GaAs as shown in Figure 1(b). The results indicate that the formation energy of internal $\mathrm{As}_{\mathrm{Ga}} \mathrm{Ga}_{\mathrm{As}}$ defect is $2.36 \mathrm{eV}$, showing an independent-position character. Note that the internal $\mathrm{As}_{\mathrm{Ga}} \mathrm{Ga}_{\mathrm{As}}$ defect is more stable than the surface $\mathrm{As}_{\mathrm{Ga}} \mathrm{Ga}_{\mathrm{As}}$ one, suggesting that formation of $\mathrm{As}_{\mathrm{Ga}} \mathrm{Ga}_{\mathrm{As}}$ deep-level defects in the crystal is easier than that on surface. 


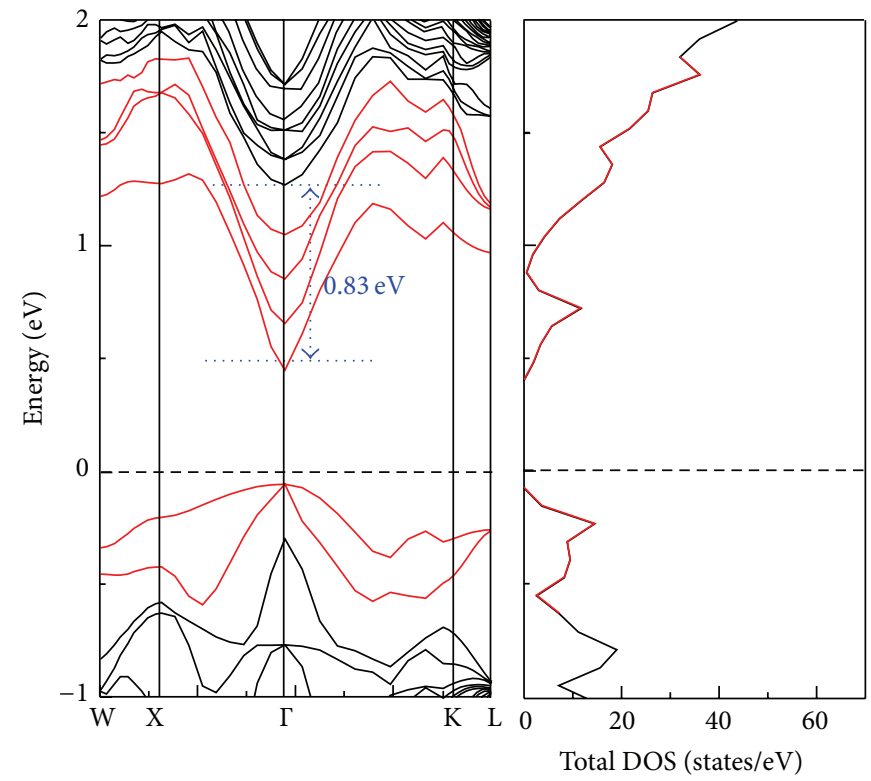

(a)
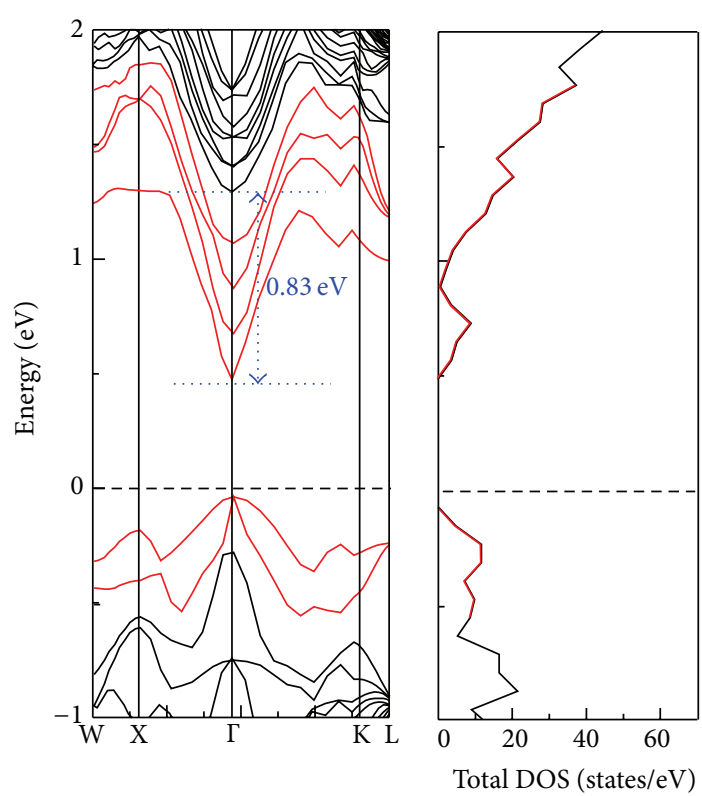

(b)

FIGURE 4: The band structure and the total DOS of GaAs with internal double antisite $\mathrm{As}_{\mathrm{Ga}} \mathrm{Ga}_{\mathrm{As}}$ defects. (a) The distance is $5.653 \AA$ between the deep $\mathrm{As}_{\mathrm{Ga}} \mathrm{Ga}_{\mathrm{As}}$ defects and the upper boundary. (b) The distance is $2.827 \AA$ between the shallow $\mathrm{As}_{\mathrm{Ga}} \mathrm{Ga}_{\mathrm{As}}$ defects and the upper boundary.

\section{Conclusions}

In this paper, we have carried out the $\mathrm{As}_{\mathrm{Ga}} \mathrm{Ga}_{\mathrm{As}}$ deeplevel defect in gallium arsenide by using first-principles calculations based on hybrid density functional theory. Our results show that the lowest donor defect level on the gallium arsenide surface is $0.85 \mathrm{eV}$ below the bottom of the conduction band, while the lowest donor defect level of the $\mathrm{As}_{\mathrm{Ga}} \mathrm{Ga}_{\mathrm{As}}$ defect inside the gallium arsenide crystal is $0.83 \mathrm{eV}$ below the bottom of the conduction band, consistent with gallium arsenide EL2 defect level of experimental value (Ec$0.82 \mathrm{eV})$. The $\mathrm{As}_{\mathrm{Ga}} \mathrm{Ga}_{\mathrm{As}}$ defect is one of the microstructures of the EL2 deep-level defects in gallium arsenide. We also found that the band structure and density of states of internal $\mathrm{As}_{\mathrm{Ga}} \mathrm{Ga}_{\mathrm{As}}$ defect have no relationship with its position and the formation energy of internal $\mathrm{As}_{\mathrm{Ga}} \mathrm{Ga}_{\mathrm{As}}$ defect is $3.16 \mathrm{eV}$, smaller than that of the defect on surface, suggesting that the formation of $\mathrm{As}_{\mathrm{Ga}} \mathrm{Ga}_{\mathrm{As}}$ deep-level defects within the crystal is easier than that of surface relatively. The existence of $\mathrm{As}_{\mathrm{Ga}} \mathrm{Ga}_{\mathrm{As}}$ defect increases donor level and acceptor level of defects and changes the total DOS of materials and atoms around the defect form the dangling bond. Consequently, the resulting surface states can exchange their positions with holes and electrons of the gallium arsenide materials, which affects the photoelectric properties of GaAs materials directly.

\section{Conflict of Interests}

The authors declare that there is no conflict of interests regarding the publication of this paper.

\section{Acknowledgments}

This work was supported by the National Natural Science Foundation of China (Grant nos. 50837005, 11304245), the Provincial Natural Science Special Foundation of Shaanxi in China (12JK0952), the Foundation of Shaanxi Key Science and Technology Innovation Team in China (2014KTC-13), the Shaanxi International Cooperation Project (2012KW04), the Dr. Startup Foundation of the Xian University of Technology in China (108-211003), and the Features Research Foundation of the Xian University of Technology in China (108-211302).

\section{References}

[1] M. J. Howes and D. V. Morgan, Gallium Arsenide: Materials, Devices, and Circuits, Wiley Series in Solid State Devices and Circuits, John Wiley \& Sons, 1985.

[2] M. Pavlović and U. V. Desnica, "Improvement in semiinsulating GaAs material quality: a comparative study of defects with deep levels," Japanese Journal of Applied Physics, vol. 37, part 1, p. 4687, 1998.

[3] U. V. Desnica, M. Skowronski, and M. C. Cretella, "Comment on 'Pair of local vibration mode absorption bands related to EL2 defects in semi-insulating GaAs' [Appl. Phys. Lett. 5 0, 1666 (1987)]," Applied Physics Letters, vol. 52, article 760, 1988.

[4] U. V. Desnica and B. Šantić, "Trap-induced photoconductivity in semi-insulating GaAs," Journal of Applied Physics, vol. 67, p. $1408,1990$.

[5] B. Šantić, D. I. Desnica, B. G. Petrović, and U. V. Desnica, "Quenching and enhancement of photoconductivity in semiinsulating GaAs," Solid State Communications, vol. 74, no. 8, pp. 847-850, 1990. 
[6] U. V. Desnica, "Persistent photocurrents in semi-insulating gallium arsenide," Radiation Effects and Defects in Solids, vol. 83, p. 111, 1989.

[7] D. Li, M. Yang, Y. Cai, S. Zhao, and Y. Feng, "First principles study of the ternary complex model of EL2 defect in GaAs saturable absorber," Optics Express, vol. 20, no. 6, pp. 6258-6266, 2012.

[8] J. Lagowski, H. C. Gatos, J. M. Parsey, K. Wada, M. Kaminska, and W. Walukiewicz, "Origin of the $0.82-\mathrm{eV}$ electron trap in GaAs and its annihilation by shallow donors," Applied Physics Letters, vol. 40, no. 4, article 342, 1982.

[9] J. F. Wager and J. A. van Vechten, "Atomic model for the EL2 defect in GaAs," Physical Review B, vol. 35, no. 5, pp. 2330-2339, 1987.

[10] Y. X. Zou, G. Y. Wang, S. Benakki, A. Goltzene, and C. Schwab, "Comment on 'atomic model for the EL2 defect in GaAs", Physical Review B, vol. 38, pp. 10953-10955, 1988.

[11] G. Y. Wang, Y. X. Zou, S. Benakki, A. Goltzene, and C. Schwab, "Identification of paramagnetic $\mathrm{As}_{\mathrm{Ga}}$ and optical EL2 centers in semi-insulating gallium arsenide," Journal of Applied Physics, vol. 63, no. 8, pp. 2595-2602, 1988.

[12] R. A. Morrow, "Model of EL2 formation in GaAs," Journal of Applied Physics, vol. 70, no. 11, pp. 6782-6789, 1991.

[13] T. Wosinski, A. Makosa, and Z. Witczak, "Transformation of native defects in bulk GaAs under ultrasonic vibration," Semiconductor Science and Technology, vol. 9, no. 11, article 2047, 1994.

[14] D. Kabiraj and S. Ghosh, “'EL2' revisited: observation of metastable and stable energy levels of EL2 in semi-insulating GaAs," Applied Physics Letters, vol. 87, Article ID 252118, 2005.

[15] Z. Y. Zhao and F. M. Wu, "Investigation on a relation between EL2 group and EL6 group in SI-GaAs," Journal of Functional Materials and Devices, vol. 2, p. 32, 1996.

[16] D. Ma, W. Shi, E. Li, L. Hou, and Y. Dai, "Structure and photoelectron energy spectrum of $\mathrm{Ga}_{2}$ Asn ion clusters," Acta Optica Sinica, vol. 29, pp. 1032-1037, 2009 (Chinese).

[17] D. M. Ma, H. B. Qiao, W. Shi, E. L. Li, Y. H. Ma, and W. Wang, "First-principles study on stability and photoelectron spectroscopy of $\mathrm{Ga}_{n} \mathrm{As}_{2}(n=1-9)$ clusters," Spectrochimica Acta A: Molecular and Biomolecular Spectroscopy, vol. 118, pp. 533537, 2014.

[18] D. M. Ma, H. B. Qiao, and E. L. Li, "Density functional theory study on stability and defect feature of Ga-rich GanAs(n=1 9) clusters," Chinese Journal of Atomic and Molecular Physics, vol. 31, pp. 223-228, 2014.

[19] D. M. Ma, H. B. Qiao, W. Shi, and E. L. Li, "Effect of the VAsVGa complex defect doping on properties of the semi-insulating GaAs," Journal of Applied Physics, vol. 115, no. 15, Article ID 153703, 2014.

[20] G. Kresse and J. Furthmüller, "Efficiency of ab-initio total energy calculations for metals and semiconductors using a plane-wave basis set," Computational Materials Science, vol. 6, no. 1, pp. 15-50, 1996.

[21] G. Kresse and J. Furthmüller, "Efficient iterative schemes for ab initio total-energy calculations using a plane-wave basis set," Physical Review B: Condensed Matter and Materials Physics, vol. 54, Article ID 11169, 1996.

[22] J. P. Perdew, K. Burke, and M. Ernzerhof, "Generalized gradient approximation made simple," Physical Review Letters, vol. 77, no. 18 , pp. 3865-3868, 1996.
[23] P. E. Blöchl, "Projector augmented-wave method," Physical Review B, vol. 50, no. 24, pp. 17953-17979, 1994.

[24] G. Kresse and D. Joubert, "From ultrasoft pseudopotentials to the projector augmented-wave method," Physical Review B: Condensed Matter and Materials Physics, vol. 59, no. 3, pp. 1758$1775,1999$.

[25] H. J. Monkhorst and J. D. Pack, "Special points for Brillouinzone integrations," Physical Review B: Solid State, vol. 13, no. 12, pp. 5188-5192, 1976. 

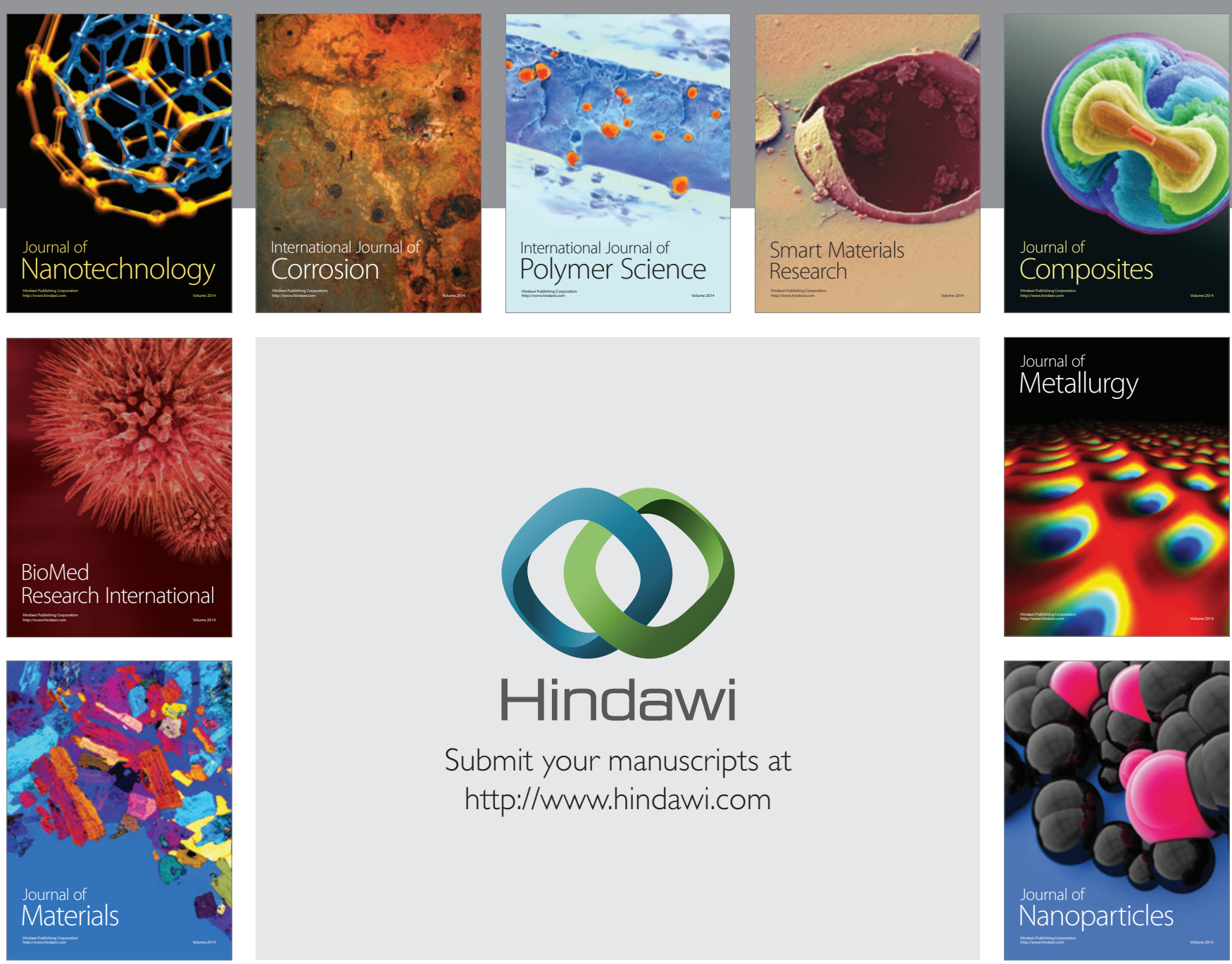

Submit your manuscripts at http://www.hindawi.com
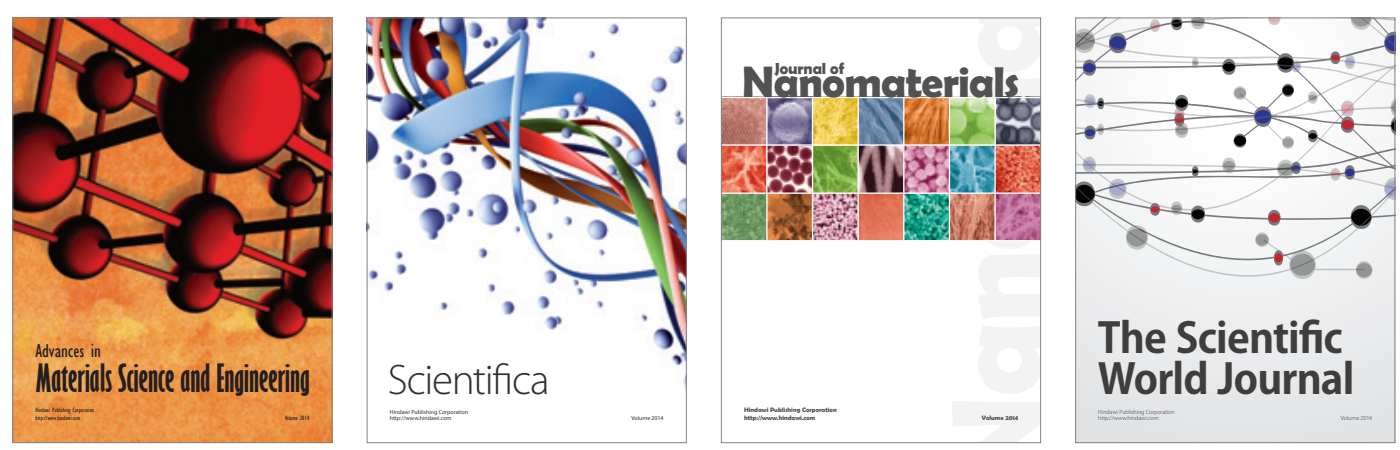

\section{The Scientific World Journal}
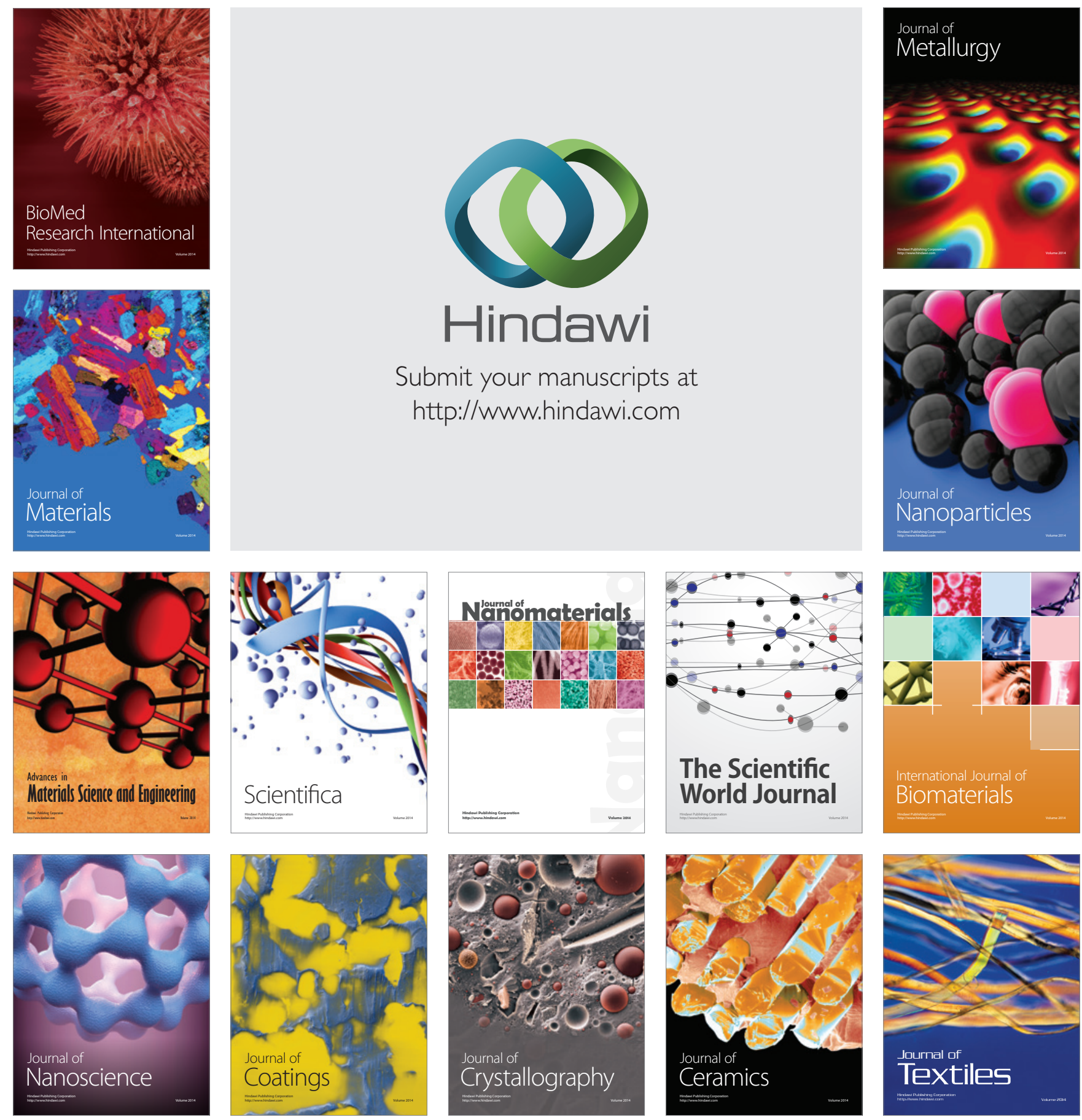